\title{
EFFECT OF AUTOMOTIVE SIDE MEMBER MATERIALS ON THE HEAD INJURY CRITERIA (HIC) AND CHEST SEVERITY INDEX (CSI) OF ADULT PASSENGER
}

\author{
M.S. Salwani ${ }^{1}$, Aidy Ali $^{2}$, B.B. Sahari ${ }^{1,3}$, A.A. Nuraini ${ }^{1}$ \\ ${ }^{1}$ Department of Mechanical and Manufacturing Engineering, Faculty of Engineering, Universiti \\ Putra Malaysia, 43400 Serdang Selangor, Malaysia.
}

${ }^{2}$ Department of Mechanical Engineering, Faculty of Engineering, Universiti Pertahanan Nasional Malaysia, Kem Sungai Besi, 57000 Kuala Lumpur, Malaysia.

${ }^{3}$ Institute of Advanced Technology, ITMA, Universiti Putra Malaysia, 43400 Serdang, Selangor, Malaysia.

Corresponding Author Email: saidynaidy@gmail.com Keywords: Automotive Side Member; Crash Analysis; Head Injury Criterion (HIC); Chest Severity
Index (CSI)

\begin{abstract}
This paper presents the results for Head Injury Criteria (HIC) and Chest Severity Index (CSI) of an adult occupant in frontal impact. The component being studied is side member as impact energy absorber. Steel side member is used as the benchmark material, whereas aluminum alloy is used as lightweight material. Crash analyses are conducted using nonlinear finite element analysis software Ls-dyna. The effect of different types of aluminum alloy and component thickness on the HIC, CSI, weight and energy absorbed is assessed and discussed. A cost function is then formulated with the geometrical average method to solve the multi-objective problem. The HIC36 and CSI are set as minimum requirements in the optimization. The materials used was Aluminium alloy of AA 5182 AA5751. It was found that AA5751 with inner and outer thickness of $2.8 \mathrm{~mm}$ and $4.9 \mathrm{~mm}$ respectively, provides a reduction in mass of $1.03 \mathrm{~kg}$ compared with steel and has energy absorbed of $11.9 \mathrm{~kJ}$. The lowest values of HIC36 and CSI obtained are 1146 and 665.4 respectively.
\end{abstract}

\section{INTRODUCTION}

Lightweight design is one of the factors to be considered in vehicle design. Lightweight design can be a means to fulfill basic requirements, such as performance and/or environmental friendliness. The energy consumption of an automobile can be reduced by reducing its weight. Steel has been extensively used in the automotive industry because of its uniqueness. Steel as an automobile body material is typically known to have good crash energy absorption qualities[1]. New materials are considered for incorporation into automobile designs for better weight efficiency. Various lightweight materials have been explored, including aluminum alloys. It has been established that an aluminum body is lighter than a steel body. The characteristic properties of aluminum such as high strength-to-weight ratio, good formability, good corrosion resistance, and recycling potential, make it the ideal candidate to replace steel in automobiles ${ }^{2}$. However, before a new material can be used, many issues need to be resolved. Crashworthiness is the crucial factor to be considered for material substitution. In an automobile crash, frontal collisions are the most frequent event, representing $62 \%$ of all collisions[3]. During a crash, automotive components are forced to absorb the transferred kinetic energy. Therefore, the crash performance of the automotive side member should be properly addressed because the automotive side member is the main energy absorber in frontal collisions.

The study of the crash characteristics and the lightweight design of the automotive side member is an important aspect of crash safety, and a series of research achievements have been made. In some studies efforts were made to improve and optimize the design in terms of weight efficiency and crush energy absorption[4-5]. A hat-type automotive side member made of 
aluminum alloy was investigated, taking into consideration the cross-sectional shape, internal stiffening and foam-filling. Li et al.[6] described a method of making automobile body parts more lightweight with high-strength steel sheets with less depth to replace the original design of mild steel under the constraint of retaining the crashworthiness of the parts. Hosseini-Tehrani and Nikahd[7] studied various simplified models of the automotive side member with a hybrid component made of steel and aluminum. Zhou et al.[8] also conducted numerical studies on the automotive side member of hybrid materials to reduce the peak impact force while increasing the total absorbed energy of the component. Salwani et. al.[9] investigated a similar side member under oblique loading.

The literature shows that substantial effort has been devoted to investigating the crash performance and lightweight design of automotive side members, but none of the discussed studies in the literature have evaluated the occupant injury assessment.

A weight reduction in automobile can be achieved by the use of alternative materials and constructive measures. However, a change in the material used usually requires changes to the component design as well. It is the objective of this paper to assess the effect of the material and component thickness changes on occupant safety.

In this study, the crash characteristics of the base model made of steel are first analyzed. Then, an aluminum alloy is introduced with AA 5182 and AA 5754 as alternative materials for the side member. Optimization is performed to maximize the energy absorbed and at the same time minimize the component weight. The mass of the base model is set as minimum requirements for the aluminum automotive side member. Lastly, an assessment of occupant safety is conducted using the Chest Severity Index (CSI) and the Head Injury Criterion (HIC).

\section{Theory}

\section{Crashworthiness}

Crash analysis generally involves impacting two bodies of known mass with specified velocity and has been described in[10]. Following a similar approach to that of ${ }^{0}$, the kinetic energy, $E_{k}$ is given by

$$
\mathrm{E}_{\mathrm{k}}=\frac{1}{2} \mathbf{m v}^{2}
$$

Where $\mathrm{m}$ is the mass and $\mathrm{v}$ is the velocity. This energy will be transferred into internal energy, $\mathrm{E}_{\mathrm{i}}$. Initially, the bodies come into contact elastically and $\mathrm{E}_{\mathrm{i}}$ is elastic, $\mathrm{E}_{\mathrm{e}}$. As the crash proceeds, plastic deformation and distortion occurs and $\mathrm{v}$ will reduce with time and plastic internal energy $\mathrm{E}_{\mathrm{p}}$ develops. To account for distortion without change of volume, hourglass energy, $\mathrm{E}_{\mathrm{h}}$ is used. The total energy $\left(\mathrm{E}_{\mathrm{t}}\right)$ in the system becomes:-

$$
E_{t}=E_{k}-E_{i}=E_{k}-E_{e}-E_{p}-E_{h}
$$

Applying the principles of energy conservation during crash event,

$$
\frac{1}{2} \mathbf{m} v^{2}=\frac{1}{2} k_{e} y_{e}^{2}+k_{p} y_{p}^{2}+E_{h}
$$

Where $k_{e}$ and $k_{p}$ are the elastic and plastic stiffness respectively and $y_{e}$ and $y_{p}$ are the elastic and plastic displacements respectively. The $\mathrm{y}_{\mathrm{p}}$ only occurs when the yield criteria of the material is satisfied. For the present study, von Mises yield criteria is used and yield occur when:-

$$
\sigma_{\mathrm{eq}}=\sqrt{\frac{3}{2} S_{\mathrm{ij}} S_{\mathrm{ij}}}=\sigma_{0}
$$

Where $\sigma_{\mathrm{eq}}$ and $\sigma_{0}$ are the equivalent and yield stress respectively. $\mathrm{S}_{\mathrm{ij}}$ is the deviatoric stresses. The plastic strain resulting from material yielding is determined from the Prandtl-Reuss flow rule; 


$$
\mathrm{d} \varepsilon_{\mathrm{ij}}=\frac{3}{2} \frac{\mathrm{d} \varepsilon_{\mathrm{p}}}{\sigma_{\mathrm{eq}}} S_{\mathrm{ij}}
$$

And,

$$
d \varepsilon_{p}=\sqrt{\frac{2}{3} d \varepsilon_{i j} d \varepsilon_{i j}}
$$

Where $\varepsilon_{\mathrm{ij}}^{\mathrm{p}}, \mathrm{d} \varepsilon_{\mathrm{ij}}^{\mathrm{p}}$ and $\mathrm{d} \varepsilon_{\mathrm{p}}$ are plastic strain, plastic strains increment and equivalent plastic strain increment respectively. For the present case, the elastic displacement $y_{\mathrm{e}}$ is very small and a 'good' mesh is developed. This resulted in $\mathrm{E}_{\mathrm{e}}$ and $\mathrm{E}_{\mathrm{h}}$ also and hence can be neglected. The internal energy expression becomes:-

$$
\mathbf{E}_{\mathbf{p}}=\mathbf{k}_{\mathrm{p}} \mathbf{y}_{\mathbf{p}}^{2}
$$

In integral form, (7), can be written as

$$
E_{p}=\int k_{p} y_{p} d y=\int F d y
$$

Where $\mathrm{F}$ is the crush force and is given by

$$
\mathbf{F}=\mathbf{k}_{\mathbf{p}} \mathbf{y}_{\mathbf{p}}
$$

The crashworthiness of an automotive body is often represented by a graph of $E_{i}$ versus time, $t$, since $\mathrm{y}_{\mathrm{p}}$ is directly proportional with $\mathrm{t}$ for steady crash. For a crash with adult passenger, the passenger safety is required to be assessed. A test into a rigid barrier with adult dummies is usually performed at a speed of $48 \mathrm{~km} / \mathrm{hr}$. A $50 \%$-Hybrid III dummy is placed in the driver seat in a belted condition. A measure of occupant injury due to impact used is the Head Injury Criteria (HIC) and Chest Severity Index (CSI). The value of the HIC is obtained by using the following equation[11].

$$
H I C=\max \left[\left(\frac{1}{t_{1}-t_{2}} \int_{t_{1}}^{t_{2}} a(t) d t\right)^{2.5}\left(t_{2}-t_{2}\right)\right]
$$

Where $a$ is the acceleration at the center of the head, $t_{1}$ and $t_{2}$ the time intervals. The values of $t_{1}$ and $\mathrm{t}_{2}$ are obtained to maximize (10). Thus, HIC is an acceleration-based value and is obtained from the time versus acceleration pulse. A dummy equivalent of the HIC value, denoted by HIC(d), is given as[12]:

$$
\operatorname{HIC}(d)=166.4+0.75446 \times \text { HIC }
$$

Similar expression to that of (10) is used for CSI except that a is the acceleration for the chest.

\section{Design of Experiments (DOE)}

DOE is a statistical tool used for more efficient selection of sampling points in the design space. In this study, a factorial design is used for its uniformity of sampling. In a full factorial design, when $\mathrm{k}$ levels are used for $\mathrm{n}$ variables, the total number of experiments is $\mathrm{k}^{\mathrm{n}}$. The present analysis dealt with 4 variables; 1) inner side member material ( $\left.\left.\mathrm{AA}_{\mathrm{inner}}\right), 2\right)$ inner side member thickness $\left.\left(\mathrm{t}_{\text {inner }}\right), 3\right)$ outer side member material $\left(\mathrm{AA}_{\text {outer }}\right)$ and4) outer side member thickness $\left(\mathrm{t}_{\text {outer }}\right)$. Table 1 lists the variables and levels used in the simulation. Accordingly, 16 experiments are generated for each of the side members made of; 1) fully AA5182; 2) fully AA5754; 3) AA5182 for the inner part and AA5754 for the outer part; and 4) AA5754 for the inner part and AA5182 for the outer part. Thus, the total number of simulations was 64 . 


\section{Optimization equations}

Crashworthiness is a very important consideration in the design of automotive components. Crashworthiness parameters are used to assess component performance. A good crashworthiness structure can absorb a high level of energy in a controlled manner without the peak force, $F_{\max }$, exceeding the allowable limit. The energy absorbed can be computed as

$$
E_{p}=\int_{0}^{y_{1}} F_{m} d y
$$

Where $\mathrm{F}_{\mathrm{m}}$ is the mean crushing force and $\mathrm{y}_{1}$ represents the total displacement for the crash event. To account for the lightweight design and crashworthiness, two objective functions are used: $f_{E A}=$ $E A(t)$ and $f_{m}=m(t)$. The optimization problem is then formulated using the geometrical average method [13]. In this method, the efficiency coefficient of these two objectives is expressed in the form of cost function $F_{E}$ : where it is required to maximize,

$$
F_{E}=\sqrt{d_{m} d_{E A}}
$$

Subjected to the following conditions:-

$$
\begin{aligned}
& \mathbf{t}^{\mathrm{L}} \leq \mathbf{t} \leq \mathbf{t}^{\mathrm{U}} \\
& \mathbf{m} \leq \mathbf{m}_{\text {const }}
\end{aligned}
$$

$t^{L}=\left(t_{1}^{L}, t_{2}^{L}, \ldots, t_{n}^{L}\right)$ and $t^{U}=\left(t_{1}^{U}, t_{2}^{U}, \ldots, t_{n}^{U}\right)$ are the lower and upper bounds of these $n$ design variables. The efficiency coefficients can be defined in terms of the relative distance to the lower bound[14]. To maximize EA, the efficiency coefficient $d_{E A}$ is calculated as Eqn. (16),

$$
d_{E A}=\frac{f_{E A}(t)-f_{E A}^{L}}{f_{E A}^{U}-f_{E A}^{L}}
$$

To minimize the weight, the efficiency coefficient $d_{m}$ is calculated using Eqn. (17),

$$
d_{m}=1-\frac{f_{m}(t)-f_{m}^{L}}{f_{m}^{U}-f_{m}^{L}}
$$

Where, $f^{L}$ and $f^{U}$ represent the lower and upper bound of the objective functions respectively. The efficiency coefficient $d_{E A}$ and $d_{m}$ vary between 0 and 1 . A value of $\mathrm{F}_{\mathrm{E}}$ equal to 1 indicates that the corresponding objective function reaches its optimal solution, and a value of $\mathrm{F}_{\mathrm{E}}$ equal to 0 indicates the worst solution.

\section{Finite element modeling}

In the present study, a single component impact simulation was carried out for the purpose of material and thickness optimization, whereas a full vehicle body simulation is done for occupant injury assessment.

\section{Geometry and finite element modeling}

The component in the present study is the automotive side member. Its location within the automotive body structure is shown in Fig. 1. The front end of the side member is connected to the cross member and the front bumper beam. The rear is connected to the vehicle chassis. The side member is a thin-walled hat-section constructed of two parts; namely, outer shell and inner shell. 
The shells are spot welded together. The simplified geometrical model of the side member and its detailed cross sections are shown in Fig. 2. For the base model, the side member is made of steel with inner shell thickness, $t_{\text {inner }}=1.6 \mathrm{~mm}$, outer shell thickness $t_{\text {outer }}=1.4 \mathrm{~mm}$ and length $800 \mathrm{~mm}$. The finite element mesh for the component, as shown in Fig. 2, is developed using Hypermesh software. The shell is modeled using a $10 \mathrm{~mm}$, 4-node Belytschko-Tsay element, and the spot-weld used is modeled as beam element. The total number of elements is 3798 .

The side member is fully fixed at right end (see Fig. 3) and crushed at the left end by a rigid wall at a speed of $48 \mathrm{~km} / \mathrm{h}$. A dynamic numerical simulation is carried out using a nonlinear finite element (FE) code LS-Dyna 971. The velocity applied conforms to Federal Motor Vehicle Safety Standard (FMVSS) 208p[14]. Contact is defined using an automatic single-surface penalty formulation.

\section{Material properties}

The materials used for the base model are steels SPRC35 for the inner shell and SAPH370F for the outer shell. The mechanical properties of the base model materials and the spot weld are given in Table 2. For aluminum, a Johnson Cook model is used, where the flow stress is expressed as;

$$
\sigma_{0}=\left(A+B \bar{\varepsilon}^{p^{n}}\right)\left(1+c \ln \dot{\varepsilon}^{*}\right)
$$

where $\mathrm{A}, \mathrm{B}, \mathrm{c}$ and $\mathrm{n}$ are input constants obtained from experimental work performed by[15]. $\bar{\varepsilon}^{p}$ is the effective plastic strain, and $\dot{\varepsilon}^{*}$ is the effective strain rate. Mechanical properties of the aluminum alloy used are also given in Table 2. For determining HIC and CSI values, a dummy is used. The skin of the head form is modeled with solid visco-elastic elements, closed with a rigid base plate and weighs approximately $4.6 \mathrm{~kg}$. The chest is modeled using visco-elastic materials. Fig. 3 shows the dummy model used and the location of accelerometers for HIC and CSI determination. The material properties are also given in Table 2.

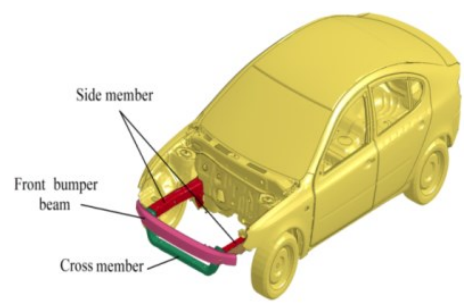

Fig. 1 Location of the automotive side member

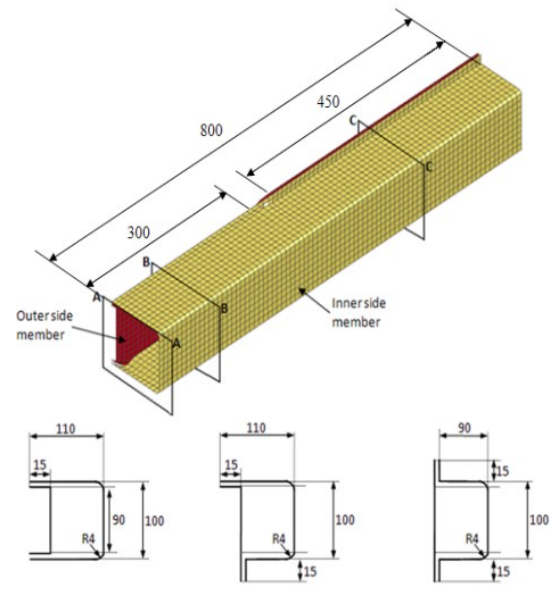

Fig. 2 Simplified automotive side member and cross-section at the (a) A-A plane, (b) B-B plane and (c) C-C plane 


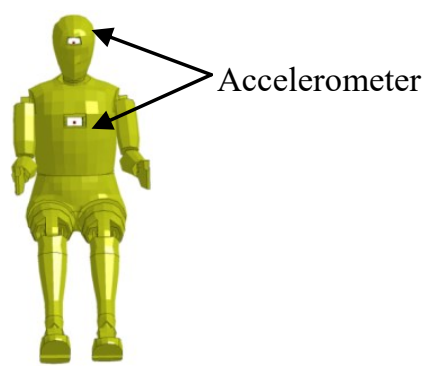

Fig. 3 Location of acceleration measuring devices

\section{RESULTS AND DISCUSSION}

\section{Crashworthiness performance of the base model}

Fig. 4(a-d) shows the deformed shapes of the base model at 0, 2.5, 35 and $60 \mathrm{~ms}$. From Fig. 4(b), it can be seen that the buckling initiated at point $A$ of the member, where the initial geometrical imperfection exists, which was followed by a fracture on the front end of the side member. Further deformation involves progressive folding across the side member between 2.5 to 30 ms. Fig. 5(a), (b) and (c) show the displacement, force and energy respectively with time. As can be seen, Fig. 5(b), a stable fluctuation in the force occurs. This finding is in agreement with observations made by[16] on metal tubes. As a result of progressive folding, the amount of energy absorbed rapidly increased (Fig. 5(c)) in that time interval. However, for the duration 30 to $60 \mathrm{~ms}$, the force then rapidly drops, and a gradual increase in the energy absorbed is observed during the global bending collapse dominating the response. It is worth noting from Fig. 5(a) that at $30 \mathrm{~ms}$, the displacement is approximately $300 \mathrm{~mm}$. This finding suggests that the bending collapse starts to dominate when the compression reaches the transaction between cross section $\mathrm{B}-\mathrm{B}$ and $\mathrm{C}-\mathrm{C}$ (refer to Fig. 3 for location A). The automotive side member is made of a long column, and therefore, even under pure axial loading, local bending collapse easily occurred, as found by Jensen et al.[17].

\section{Crashworthiness of Aluminum side member}

The crashworthiness of a lightweight design can be improved through material selection and component design. In this section, a parametric study is carried out to find the most suitable aluminum alloy for the automotive side member. A full factorial design is employed. Finite element simulation is performed to obtain the energy absorbed, EA, and mass, $m$, for each of the 64 designs.

The simulation results are shown in Table 3. Generally, it can be observed that the side member made of AA5182 is superior to the member made of AA5754 in all designs. Furthermore, the side member made of AA5182 is also found to be efficient at absorbing energy at a low mass. However, as the mass of the AA5182 side member increased, the energy absorbed is comparable to the side member made of a combined aluminum alloy.

\section{Design optimization}

The geometrical average method is applied to solve the multi-objective problem. In this method, a cost function is built by utilizing the relative efficiency of each objective in terms of a geometrical average as

$$
\text { Maximize } F_{E}=\sqrt{d_{m} d_{E A}}
$$

Subjected to the conditions:-

$2.8 \mathrm{~mm} \leq \mathrm{t}_{\text {inner }} \leq 4.6 \mathrm{~mm}$ 
$3.1 \mathrm{~mm} \leq \mathrm{t}_{\text {outer }} \leq 4.9 \mathrm{~mm}$

$m \leq 4.2 \mathrm{~kg}$

The efficiency cost function, $F_{E}$, $\left(t_{\text {inner }}, t_{\text {outer }}\right)$ versus the design variables is plotted in Fig. 6(a) to (d). Through the formulation of a cost function, the multi-objective problem is transformed into a single-objective problem. It is interesting to note that the response pattern of Fig. 6(a) is almost identical to Fig. 6(c), while Fig. 6(b) is identical to Fig. 6(d). This is because the same material is used for the inner side member, which is AA5182 for 7(a) and 7(c) and AA5754 for 7(b) and 7(d), respectively. The inner side member is proven to have a significant effect on $F_{E}$ because it is carrying a bigger percentage of the total mass, and thus the energy absorbed, by the component.

The results for several designs with a score of 0.7 and above for $d_{m}, d_{E A}$ and $F_{E}$ are given in Table 4. Based on $F_{E}$ score, n_1112, n_2124 and n_1121 have the highest scores for side member made of fully AA5182, fully AA5754 and a combination of the two materials, respectively. In order for aluminum to be well accepted in the automotive industry, it should have superior performance compared with its steel counterparts. Considering the constraint imposed, n_1111, n_1112, and $\mathrm{n} \_1113$ outperformed the base model in weight and also energy absorption capability. Overall, it can be concluded that $n_{-} 1112$ is the optimal design with a total efficiency coefficient of 0.95 .Even though the $n \_1112$ and $n \_1122$ designs have the same mass, the side member made of AA5182, $\mathrm{n} \_1112$, is better at absorbing energy than the side member made of the combined material, $\mathrm{n} \_1122$. Fig. 7 shows that n_1112 absorbs energy more efficiently through formation of several folds and less fracturing compared with $\mathrm{n}_{-}$1122. In comparison to the base model, side members made of aluminum alloys successfully brought the displacement to a halt before it reached $300 \mathrm{~mm}$, the distance where bending dominating the collapse behavior in the base model. Referring to Fig. 8, at $55 \mathrm{~ms}$, the reaction force for $\mathrm{n}_{-} 1111, \mathrm{n} \_1112$ and $\mathrm{n} \_1113$ has returned to zero, and all the energy transferred to the side member is fully absorbed. In contrast, the base model is still reacting to the energy transferred through plastic deformation.

\section{Occupant safety}

As the public becomes increasingly aware that safety is a very important issue, more stringent requirements are being placed on car manufacturers to limit the injuries to occupant in a potential crash event. There are two major mechanical causes of the various mechanisms leading to injuries. One is a direct impact involving the collision of a human body with another solid object at an appreciable velocity, and the other is a noncontact impact involving a sudden body motion without direct contact with another solid object ${ }^{0}$. It was be observed the contact between the dummy chests and the steering wheel. At $5 \mathrm{~ms}$, the car is hitting the rigid wall. Between 5 to $60 \mathrm{~ms}$, the car is moving forward, and compression of the frontal structure occurs. However, at approximately $60 \mathrm{~ms}$, the car has started to bounce back. The dummy chest hits the steering at approximately $60 \mathrm{~ms}$ and $70 \mathrm{~ms}$ for the aluminum and steel models, respectively.

Head injury remains one of the most frequent and severe sustained by vehicle occupants in road accidents and accounts for approximately $40 \%$ of road fatalities in the European Union[18]. Fig. 10 shows the acceleration pattern for the base and n_1112 models. HIC36 respond to the acceleration in $15 \mathrm{~ms}$ and $36 \mathrm{~ms}$ time intervals, respectively, at the highest value. The $\mathrm{n} 1112$ model indicates a lower potential of injury for all criteria assessed. It is also interesting to note from Table 4 that, even though side member made of fully AA5754, n_2124 do not absorbed as much energy as n_1112 in a component impact, but it shows outstanding performance in terms of occupant protection. Model n_2124 gave the lowest value of HIC36 of 1146 .

For restrained drivers, the CSI parameter proved to be a strong predictor of occupant injury because it reflects both the way the front end of the car crushes and the performance characteristics of the seat belt[14]. The CSI is obtained during a $3 \mathrm{~ms}$ period. Both steel and aluminum side members exhibited almost the same pattern. Based on these general requirements, the National 
Highway Traffic Safety Administration (NHTSA) produced corresponding legislation described in the Federal Motor Vehicle Safety Standard No 208 for occupant crash protection. The biomechanical load limits in impact load cases for a 50\% -Hybrid III dummy cannot exceeds 60 g's for the acceleration value[19]. The CSI for the $\mathrm{n}$-1112 conforms to the regulation; the acceleration does not exceed the limit as shown in Fig. 10. The values of CSI for obtained for other selected geometries are shown in Table 4. For CSI, n_2124 gives the lowest value of 665.4 compared with the others followed by $n \_1112$ with CSI value of 700.6 . It can be noted that, again although n_1112 absorbs higher EA, it does not give lower CSI. This indicated that the biomechanical response of occupant is more complex compared with material response to impact.

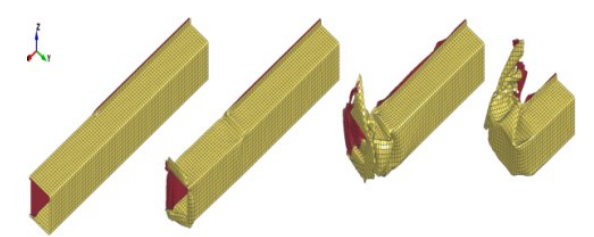
(a)
(b)
(c)
(d)

Fig. 4 Collapse behavior at (a) 0, (b) 2.5, (c) 35 and (d) $60 \mathrm{~ms}$

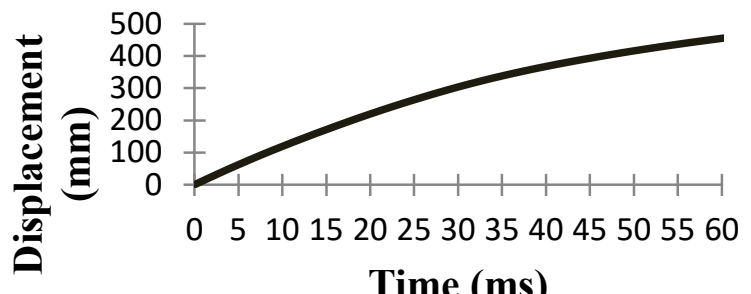

(a)

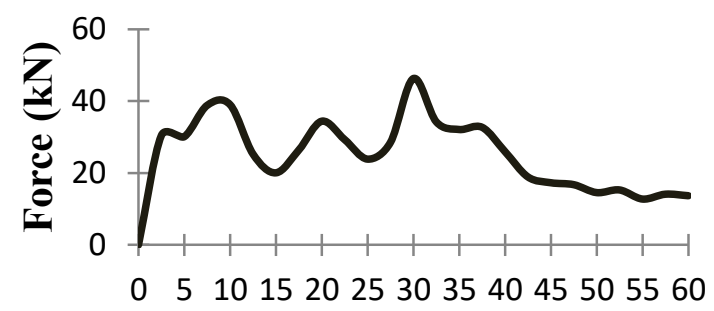

Time (ms)

(b)

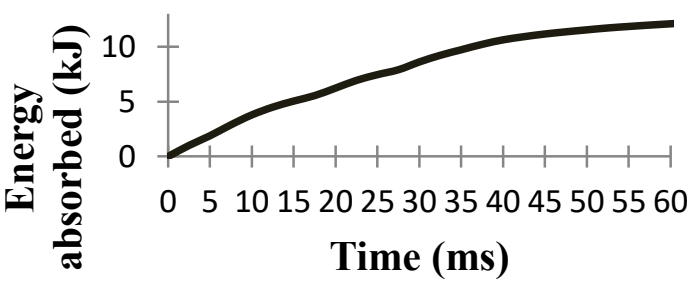

(c)

Fig. 5 Impact response of automotive side member 

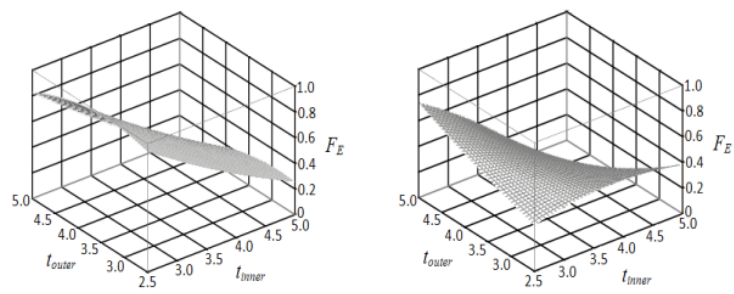

(a)
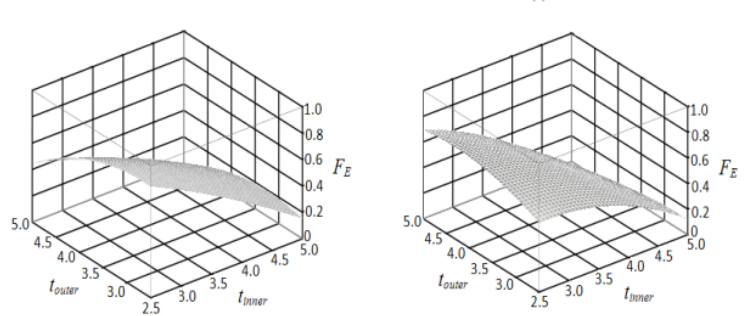

(c)

(d)

Fig. 6 Response surface of the efficiency cost function for (a) fully AA5182; (b) fully AA5754; (c) inner side member (AA5182) and outer side member (AA5754); and (d) inner side member (AA5754) and outer side member (AA5182).

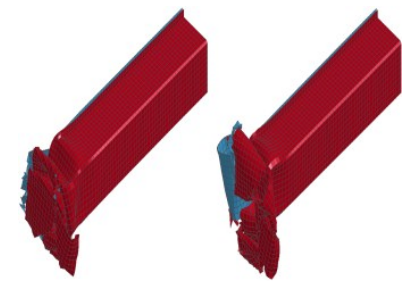

(a)

(b)

Fig.7 Comparison of crash pattern between (a) base model and (b) n_1112

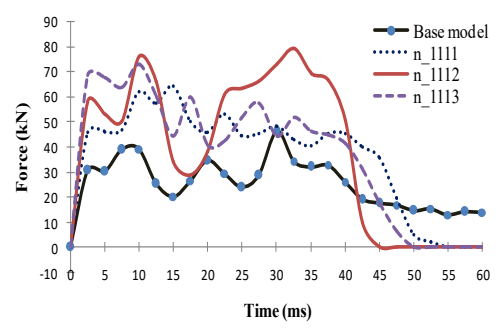

(a)

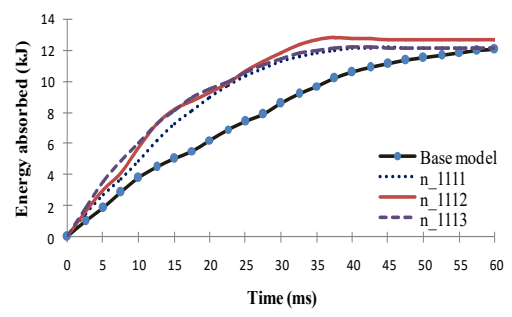

(b)

Fig. 8 Comparison between n_1111, n_1112, n_1113 and the base model in terms of the (a) force response and the (b) absorbed energy 


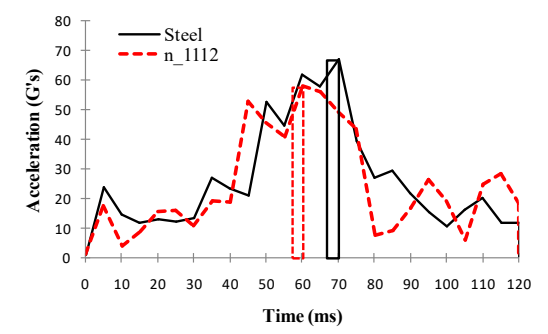

Fig. 9 Chest Severity Index value obtained from the dummy model

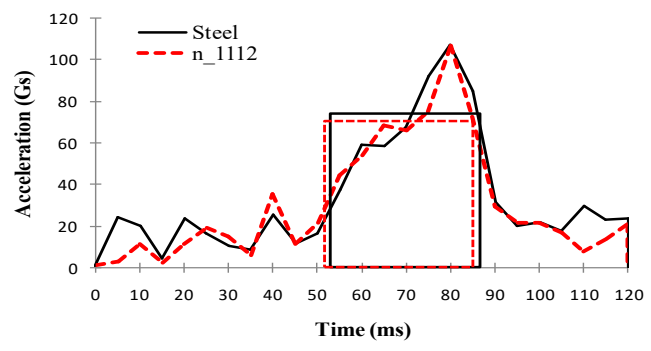

Fig. 10 Values obtained from the dummy model for HIC36.

Table 1 Design levels in the simulation

\begin{tabular}{ccccc}
\hline Level & $\boldsymbol{A}_{\text {inner }}$ & $\boldsymbol{t}_{\text {inner }}(\mathbf{m m})$ & $\boldsymbol{A}_{\text {outer }}$ & $\boldsymbol{t}_{\text {outer }}(\mathbf{m m})$ \\
\hline 1 & AA 5182 & 2.8 & AA 5182 & 3.1 \\
2 & AA 5754 & 3.4 & AA 5754 & 3.7 \\
3 & - & 4.0 & - & 4.3 \\
4 & - & 4.6 & - & 4.9 \\
\hline
\end{tabular}

Table 2 Materials used and their mechanical properties

\begin{tabular}{cccccccccc}
\hline $\begin{array}{c}\text { Material } \\
\text { model }\end{array}$ & $\begin{array}{c}\text { Material } \\
\text { types }\end{array}$ & $\begin{array}{c}\mathbf{E} \\
(\mathbf{G P a})\end{array}$ & $\mathbf{v}$ & $\begin{array}{c}\boldsymbol{\sigma}_{\mathbf{y}} \\
\mathbf{( M P a )}\end{array}$ & $\begin{array}{c}\mathbf{\rho} \\
\left(\mathbf{k g} / \mathbf{m}^{\mathbf{3}}\right)\end{array}$ & $\mathbf{A}$ & $\mathbf{B}$ & $\mathbf{c}$ & $\mathbf{n}$ \\
\hline $\begin{array}{c}\text { Piecewise } \\
\text {-Linear- }\end{array}$ & SPRC35 & 206.0 & 0.30 & 233.0 & 7850 & NA & NA & NA & NA \\
Plasticity & SAPH370F & 206.0 & 0.30 & 254.0 & 7850 & NA & NA & NA & NA \\
$\begin{array}{c}\text { Simplified } \\
\text { Johnson- }\end{array}$ & AA 5182 & 69.6 & 0.33 & 135.0 & 2650 & 106.74 & 659.12 & -0.001 & 0.485 \\
\begin{tabular}{c} 
Cook \\
\hline
\end{tabular} & AA 5754 & 70.0 & 0.33 & 130.0 & 2650 & 67.46 & 471.24 & 0.003 & 0.424 \\
\hline
\end{tabular}

Table 3 Results of the 64 simulations

\begin{tabular}{|c|c|c|c|c|c|}
\hline $\mathrm{n}^{*}$ & $\begin{array}{c}\text { Mass } \\
(\mathrm{kg})\end{array}$ & $\begin{array}{c}\text { Energy } \\
\text { absorbed (kJ) }\end{array}$ & $n *$ & $\begin{array}{c}\text { Mass } \\
(\mathrm{kg})\end{array}$ & $\begin{array}{c}\text { Energy } \\
\text { absorbed } \\
(\mathbf{k J})\end{array}$ \\
\hline 1111 & 2.67 & 12.11 & 2111 & 2.68 & 11.19 \\
\hline 1112 & 2.83 & 12.69 & 2112 & 2.84 & 11.46 \\
\hline 1113 & 2.99 & 12.13 & 2113 & 3.00 & 11.55 \\
\hline 1114 & 3.15 & 11.91 & 2114 & 3.16 & 11.54 \\
\hline 1121 & 2.67 & 11.69 & 2121 & 2.69 & 10.56 \\
\hline 1122 & 2.83 & 11.63 & 2122 & 2.85 & 10.83 \\
\hline 1123 & 3.00 & 11.29 & 2123 & 3.01 & 11.04 \\
\hline 1124 & 3.16 & 10.71 & 2124 & 3.17 & 11.90 \\
\hline 1211 & 3.06 & 11.50 & 2211 & 3.07 & 11.31 \\
\hline 1212 & 3.22 & 11.73 & 2212 & 3.23 & 10.96 \\
\hline 1213 & 3.38 & 11.95 & 2213 & 3.39 & 12.05 \\
\hline
\end{tabular}




\begin{tabular}{llllll}
\hline 1214 & 3.54 & 11.69 & 2214 & 3.55 & 11.82 \\
1221 & 3.06 & 11.35 & 2221 & 3.08 & 10.60 \\
1222 & 3.22 & 11.62 & 2222 & 3.24 & 10.96 \\
1223 & 3.38 & 10.81 & 2223 & 3.40 & 11.12 \\
1224 & 3.54 & 10.97 & 2224 & 3.56 & 10.73 \\
1311 & 3.44 & 11.60 & 2311 & 3.46 & 10.98 \\
1312 & 3.60 & 11.47 & 2312 & 3.62 & 11.14 \\
1313 & 3.76 & 11.28 & 2313 & 3.78 & 11.39 \\
1314 & 3.92 & 11.25 & 2314 & 3.94 & 11.10 \\
1321 & 3.45 & 10.97 & 2321 & 3.47 & 11.01 \\
1322 & 3.61 & 11.38 & 2322 & 3.63 & 10.82 \\
1323 & 3.77 & 11.08 & 2323 & 3.79 & 10.61 \\
1324 & 3.93 & 11.03 & 2324 & 3.95 & 10.44 \\
1411 & 3.83 & 11.29 & 2411 & 3.85 & 10.70 \\
1412 & 3.99 & 11.33 & 2412 & 4.01 & 11.17 \\
1413 & 4.15 & 11.61 & 2413 & 4.17 & 10.89 \\
1414 & 4.31 & 11.43 & 2414 & 4.33 & 11.36 \\
1421 & 3.84 & 11.09 & 2421 & 3.86 & 11.01 \\
1422 & 4.00 & 11.38 & 2422 & 4.02 & 10.12 \\
1423 & 4.16 & 11.22 & 2423 & 4.18 & 10.39 \\
1424 & 4.32 & 10.77 & 2424 & 4.34 & 10.52
\end{tabular}

*n is the design pattern. Four integers in a pattern represent level of the variables (Refer to Table 1). First integer for $\mathrm{AA}_{\text {inner }}$ level, second integer for $\mathrm{t}_{\text {inner }}$ level, third integer for $\mathrm{AA}_{\text {outer }}$ level and fourth integer for $t_{\text {outer }} l e v e l$.

Table 4 Results of the geometrical average method and its injury criteria

\begin{tabular}{ccccccccc}
\hline $\mathbf{n}$ & $\boldsymbol{d}_{\boldsymbol{m}}$ & $\boldsymbol{d}_{\boldsymbol{E A}}$ & $\boldsymbol{F}_{\boldsymbol{E}}$ & $\begin{array}{c}\mathbf{P}_{\mathbf{m a x}} \\
(\mathbf{k N})\end{array}$ & $\begin{array}{c}\mathbf{m} \\
(\mathbf{k g})\end{array}$ & $\begin{array}{c}\text { EA } \\
(\mathbf{k J})\end{array}$ & HIC36 & CSI \\
\hline Base model & 0.08 & 0.76 & 0.25 & 30.40 & 4.20 & 12.07 & 1474 & 795.6 \\
1111 & 1.00 & 0.77 & 0.88 & 62.12 & 2.67 & 12.11 & 1753 & 798.5 \\
1112 & 0.90 & 1.00 & 0.95 & 58.06 & 2.83 & 12.69 & 1305 & 700.6 \\
1113 & 0.81 & 0.78 & 0.80 & 68.47 & 2.99 & 12.13 & 1167 & 920.0 \\
1114 & 0.71 & 0.70 & 0.70 & 75.28 & 3.15 & 11.91 & 1283 & 999.5 \\
2124 & 0.70 & 0.69 & 0.70 & 70.00 & 3.17 & 11.90 & 1146 & 665.4 \\
1121 & 1.00 & 0.61 & 0.78 & 58.45 & 2.67 & 11.69 & 1214 & 893.7 \\
1122 & 0.90 & 0.59 & 0.73 & 65.00 & 2.83 & 11.63 & 1445 & 1147 \\
\hline
\end{tabular}

\section{CONCLUSIONS}

In this paper, a full factorial design generates 64 designs for analysis. A side member made of steel provides a baseline for the constraint setting. Two types of aluminum alloy are used for the component, and two design variables are investigated: the mass and the energy absorbed. The performance of the aluminum alloy side member is optimized with the geometrical average method. From the above discussions, the following conclusions were made: 
i. At the same mass, the side member made of AA5182 is superior to that made of AA5754 in terms of energy absorbed.

ii. The optimal design is found to be $\mathrm{n} 1112$ when mass and energy absorbed is taken into consideration. Introduction of AA518 2 in $n \_1112$ provides $32.62 \%$ weight reduction, while the energy absorbed is increased by $5.14 \%$ compared with its steel counterparts.

iii. The design n_2124 is found to be suitable for lowest value of HIC36 of 1146 and lowest value of SCI of $6 \overline{6} 5.4$ with a weight of $1.03 \mathrm{~kg}$ less than steel side members.

iv. AA5754 shows better performance in terms of occupant protection compared with AA5182.

v. Aluminum alloy is able to reduce the weight of side member and improved the energy absorbed and the occupant protection.

\section{ACKNOWLEDGEMENTS}

The authors would like to thank the Ministry of Science, Technology and Innovation (MOSTI), Malaysia for providing the research grant under TechnoFund [TF-0608C073], Collaborative Institutions (UKM, UM, UTM and UniKL, PROTON and MIMOS) for the support provided under the COFEC-Car Project and Universiti Putra Malaysia for providing the facilities.

\section{REFERENCES}

[1]. Davies G (2003): Materials for consideration and use in automotive body structures, Materials for Automobile Bodies. Butterworth-Heinemann, Oxford, pp. 61-98

[2]. Miller WS, Zhuang L, Bottema J, Wittebrood AJ, De Smet P, Haszler A, Vieregge A, Recent development in aluminium alloys for the automotive industry, Materials Science and Engineering A, 280 (2000) 37-49.

[3]. Scheunert D, Justen R, Herrmann R, Zeidler F, Decker J, Kallina I, What is a realistic frontaloffset test procedure?, Accident Analysis \& Prevention, 26 (1994) 347-360.

[4]. Kim H-S, Wierzbicki T, Effect of the cross-sectional shape of hat-type cross-sections on crash resistance of an "S"-frame, Thin-Walled Structures, 39 (2001) 535-554.

[5]. Kim H-S,, Analysis of crash response of aluminium foam-filled front side rail of a passenger car, International Journal of Crashworthiness, 6 (2001) 189 - 208.

[6]. Li Y, Lin Z, Jiang A, Chen G, Use of high strength steel sheet for lightweight and crashworthy car body, Materials \& Design, 24 (2003) 177-182.

[7]. Hosseini-Tehrani $P$, Nikahd $M$, Two materials S-frame representation for improving crashworthiness and lightening, Thin-Walled Structures, 44 (2006) 407-414.

[8]. Zhou Y, Lan F, Chen J, Crashworthiness research on S-shaped front rails made of steelaluminum hybrid materials, Thin-Walled Structures, 49 (2011) 291-297.

[9]. Salwani M. S., Aidy Ali, Sahari B. B. and Nuraini A. A.,Crash of automotive side member subjected to oblique loading, International Journal of the Physical Sciences, Vol. 6(31),(2011), $7125-7131$.

[10]. Sahari B. B., Norwazan A. R., Hamouda A. M., Khalid Y. A.,, and Wong S. V., The effect of bulge height and length on the lateral crash behaviour of front platform of a compressed natural gas vehicle, Int. J. Vehicle Safety, Vol. 2, No. 3, (2007),278-287.

[11]. Gong SW, Lee HP, Lu C, Computational simulation of the human head response to noncontact impact, Computers \& Structures, 86 (2008) 758-770.

[12]. Deb A, Gupta NK, Biswas U, Mahendrakumar MS, Designing for head impact safety using a combination of lumped parameter and finite element modeling, International Journal of Crashworthiness, 10 (2005) 249-257. 
[13]. Hou S, Li Q, Long S, Yang X, Li W, Multiobjective optimization of multi-cell sections for the crashworthiness design, International Journal of Impact Engineering, 35 (2008) 1355-1367.

[14]. Jones I. S, Whitfield R. A, Predicting injury risk with "New Car Assessment Program" crashworthiness ratings, Accident Analysis \& Prevention, 20 (1988) 411-419.

[15]. Smerd R, Winkler S, Salisbury C, Worswick M, Lloyd D, Finn M, High strain rate tensile testing of automotive aluminum alloy sheet, International Journal of Impact Engineering, 32 (2005) 541-560.

[16]. Sadighi M, Mahmoudabadi MZ, Karamnejad A, A quasi-static and low-velocity impact crushing investigation on a metal square tube, Proceedings of the Institution of Mechanical Engineers, Part C: Journal of Mechanical Engineering Science, 225 771-779.

[17]. Jensen $\varnothing$, Langseth M, Hopperstad OS, Experimental investigations on the behaviour of short to long square aluminium tubes subjected to axial loading, International Journal of Impact Engineering, 30 (2004) 973-1003.

[18]. Deck C, Willinger R, Improved head injury criteria based on head FE model, International Journal of Crashworthiness, 13 (2008) 667-678.

[19]. Oct. 1, 2004: Code of Federal Regulations (CFR), Title 49 - Transportation, Chapter V National Highway Traffic Safety Administration, Department of Transportation, Part 571 Federal Motor Vehicle Safety Standards, §571.208 Standard No. 208 - Occupant Crash Protection., U. S. Government Printing Office. 